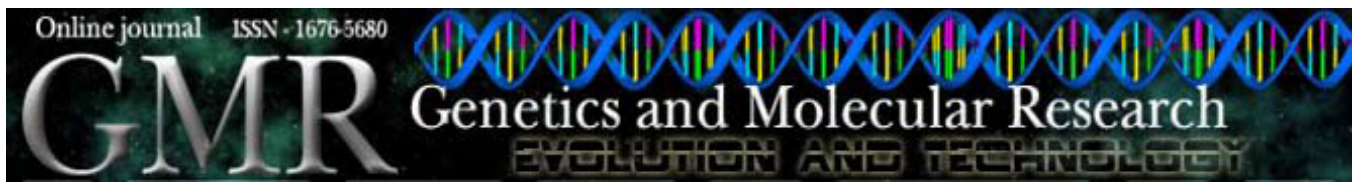

\title{
Genetic diversity among Zygophyllum (Zygophyllaceae) populations based on RAPD analysis
}

\author{
I. Hammad ${ }^{1}$ and S.H. Qari ${ }^{2}$ \\ ${ }^{1}$ Department of Microbiology and Botany, Faculty of Science, \\ Helwan University, Egypt \\ ${ }^{2}$ Department of Biology, University College, Umm Al-Qura University, \\ Makah, Saudi Arabia \\ Corresponding author: I. Hammad \\ E-mail: hammadibtisam@yahoo.com
}

Genet. Mol. Res. 9 (4): 2412-2420 (2010)

Received November 8, 2010

Accepted November 16, 2010

Published December 14, 2010

DOI 10.4238/vol9-4gmr1144

\begin{abstract}
Zygophyllum species are succulent plants that are drought resistant and/or salt tolerant, growing under severe, dry climatic conditions. Despite their importance and abundance in the Mediterranean and Middle East regions, there is little information concerning molecular variations among species of this genus. Genetic diversity was assessed, using RAPD primers, of 12 populations of Z. coccineum, Z. album and $Z$. aegyptium collected from various locations in Egypt and Saudi Arabia. Yong leaves were used for DNA extraction. Genetic distances were calculated using Nei's method. A dendrogram was constructed based on the similarity data matrix by unweighted pair group method using arithmetic averages cluster analysis. Analysis with RAPD markers revealed genetic variation between and within populations of Zygophyllum. Zygophyllum coccineum showed higher levels of genetic variation and more unique alleles than the other species.
\end{abstract}

Key words: Zygophyllum coccineum; Z. album; Z. aegyptium; RAPD; Genetic distances; Diversity 


\section{INTRODUCTION}

Zygophyllum belongs to the Zygophyllaceae family. Species belonging to this genus represent a group of succulent plants that are drought resistant and/or salt tolerant, living under severe, dry climatic conditions; moreover, it is recorded by many authors (for ex., Batanouny and Ezzat, 1971) as one of the important components of the desert vegetation. The abundance of species related to this genus could be attributed to their high tolerance to environmental stresses in addition to their unpalatability. The growth and distribution of Zygophyllum species are attributed to their dependence on the chemical nature of the soil of their habitats (Batanouny and Ezzat, 1971). Zygophyllum coccineum is the most widespread Zygophyllum species in Egypt and Saudi Arabia, where it occupies diverse habitats and shows wide soil range. The plant is very common in the limestone wades and plains of the Eastern (Arabian) desert and tolerant of saline soils. It dominates a community of widespread occurrence there. It is a small perennial herb with fleshy leaves and somewhat whitish flowers of saline and sandy habitats near the sea. Flowering time is October-November (Batanouny and Ezzat, 1971). Zygophyllum album is a succulent cushion-like undershrub frequently reaching $1 \mathrm{~m}$ in height. The leaves and branches are blue-green, mealy pubescent, and present in oases, eastern Egyptian desert, Red sea coastal region, and Sinai (Tackholm, 1974). Hoseny (2005) studied the size structure of Z. album populations in relation to its physiographic and soil conditions in Salhyia area (N.E. Nile Delta, Egypt). Zygophyllum aegyptium is an important taxon endemic to the Mediterranean costal region of the Nile Delta (Egypt). It is a perennial woody undershrub with evergreen succulent leaves. There is a debate regarding the taxonomy of this species and that of Z. album. Hosny (1977) and El-Hadidi (1978) stressed this issue using morphological characters as taxonomical descriptors. Other studies on this genus focused on its ecology (Mashaly, 2002), on cytological studies (Soliman, 1995; Ahmed, 2001) and on biochemical studies (Ait El Cadi et al., 2008; Landi et al., 2008). There are few reports dealing with molecular studies (Beier et al., 2003).

Molecular markers could reflect the difference between species (Wang et al., 1996). Several molecular markers particularly the random amplified polymorphic DNA (RAPD), restriction fragment length polymorphism and variable number of tandem repeats have been proven useful in detecting genetic diversity of plants. RAPDs are dominant molecular markers developed by Welsh and McClelland (1990) and Williams et al. (1990). These markers are random pieces of DNA amplified from the genome by a polymerase chain reaction (PCR)based technique. RAPD profiling uses single-short oligonucleotide primers (10 bases) and Taq DNA polymerase to amplify DNA segments between priming sites. Amplified DNA fragments may be visualized on electrophoresis gels, and bands scored as presence or absence character states. RAPD profiling is being increasingly used in population surveys because of the ease of methodology and the numerous polymorphic, distinguishable bands (Stewart Jr. and Excoffier, 1996). Several studies have used RAPDs to assess levels and patterns of variation with different plants (Chalmers et al., 1992; Huff et al., 1993; Landry et al., 1993; Nesbitt et al., 1995; Esselman et al., 1999; Prathepha and Baimai, 1999; Navarro-Quezada et al., 2003; Nasser and Al-Khalifah, 2004; Chaturvedi and Nag, 2010; Salim et al., 2010). This study used RAPD markers to investigate the distribution of genetic variability in natural populations of three species of Zygophyllum in Egypt and Saudi Arabia. Therefore, the aims of this study are to develop RAPD fingerprint for characterizing and detecting polymorphism among different populations of these species and to investigate the genetic relationships among these species. 


\section{MATERIAL AND METHODS}

\section{Plant materials}

A total of 12 populations of three species of Zygophyllum were collected from Egypt and Saudi Arabia. Zygophyllum coccineum was represented by seven populations, Z. album was represented by 4 populations while $Z$. aegyptium was represented by only one population (Table 1 and Figure 1). Young leaves were harvested and placed in a sealable plastic bag with appropriate label. The collected leaves were used for DNA extraction, while excess leaf materials were stored at $-80^{\circ} \mathrm{C}$ for future DNA extraction. Total genomic DNA was extracted from leaves using a modified CTAB method based on the protocol of Doyle and Doyle (1990). Quality and concentration of total DNA was verified by UV spectrophotometer at 260 and $280 \mathrm{~nm}$. Further quality of DNA was tested by submerged horizontal agarose gel $(0.8 \%)$ electrophoresis and visualized under UV light, gel documentation system. The experiment was repeated three times and reproducible RAPD bands were used for further analysis.

\begin{tabular}{|c|c|c|}
\hline Population ID & Scientific name & Location \\
\hline Loc1 & Z. coccineum & Ras Abu-rudeis, Sinai, Egypt \\
\hline Loc2 & Z. coccineum & Abu-zenima, Sinai, Egypt \\
\hline Loc3 & Z. coccineum & Ras-sedr, Sinai, Egypt \\
\hline Loc4 & Z. coccineum & Al suaz, Egypt \\
\hline Loc5 & Z. coccineum & Wadi-hofe, Helwan, Egypt \\
\hline Loc6 & Z. coccineum & Alshoayba, Gizan, Saudi Arabia \\
\hline Loc7 & Z. coccineum & Alshoayba, Gizan, Saudi Arabia \\
\hline Loc8 & Z. album & Abu-rudeis, Sinai, Egypt \\
\hline Loc9 & Z. album & Ras-suder, Sinai, Egypt \\
\hline Loc10 & Z. album & Alshoayba, Gizan, Saudi Arabia \\
\hline Loc11 & Z. album & Alshoayba, Gizan, Saudi Arabia \\
\hline Loc12 & Z. aegyptium & Demitta, Delta, Egypt \\
\hline
\end{tabular}
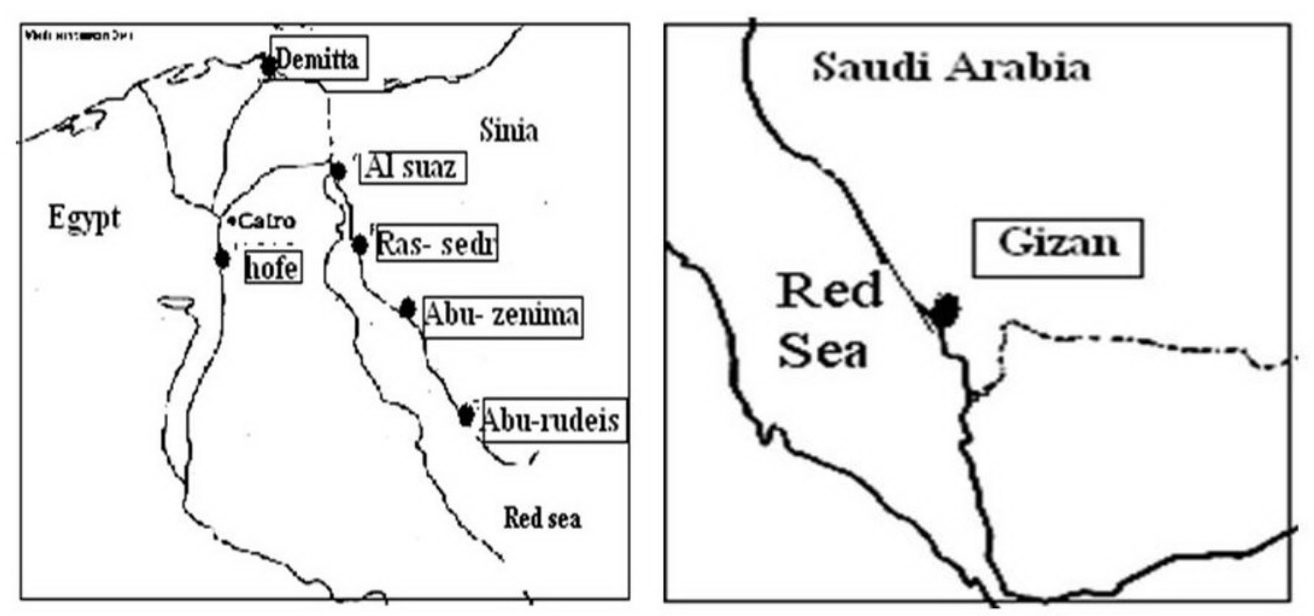

Figure 1. Map of Egypt and Saudi Arabia indicating the localities where Zygophyllum populations of the three species were collected. Filled rectangles indicate the location of the seven main areas from which samples were collected. 


\section{RAPD analysis}

Ten random decamer primers (Operon Technologies, USA) of OPA, OPB, OPE, OPG, and OPZ series were used individually as primers for RAPD analysis. The PCR amplification was carried out at Genetics Laboratory, at Helwan University, Egypt. Eight arbitrary 10-base primers were selected for PCR amplification. Amplification reactions were performed with 25 $\mu \mathrm{L} 10 \mathrm{X}$ assay buffer, $2.0 \mu \mathrm{L} 1.25 \mathrm{mM}$ each dNTP, $15 \mathrm{ng}$ of the primer, $1 \mathrm{X}$ Taq polymerase buffer, 0.5 units Taq DNA polymerase (TaKaRa), $2.5 \mathrm{mM} \mathrm{MgCl}_{2}$, and $30 \mathrm{ng}$ genomic DNA. DNA amplification was performed in a Perkin Elmer Cetus 480 DNA Thermal Cycler programmed for 45 cycles as follows: 1 st cycle of $3.5 \mathrm{~min}$ at $92^{\circ} \mathrm{C}, 1 \mathrm{~min}$ at $35^{\circ} \mathrm{C}, 2 \mathrm{~min}$ at $72^{\circ} \mathrm{C}$; followed by 44 cycles each of $1 \mathrm{~min}$ at $92^{\circ} \mathrm{C}, 1 \mathrm{~min}$ at $35^{\circ} \mathrm{C}, 2 \mathrm{~min}$ at $72^{\circ} \mathrm{C}$ followed by one final extension cycle of $7 \mathrm{~min}$ at $72^{\circ} \mathrm{C}$. The amplification products were separated by electrophoresis on $1.2 \%(\mathrm{w} / \mathrm{v})$ agarose gels with $0.5 \mathrm{X}$ TBE buffer, stained with $0.2 \mathrm{mg} / \mathrm{mL}$ ethidium bromide. A DNA ladder was used as molecular standards and the bands were visualized and analyzed by the JD-801 Gel Electrophoresis Image Analytic System (Jiangsu, China). All reactions were repeated at least twice.

\section{Data analysis}

Evaluation of fragment patterns was carried out by similarity index. Reproducible bands were scored manually as ' 1 ' or ' 0 ' for presence or absence of the bands. The data were used for similarity-based analysis using the NTSYS (2.20) software program. RAPD analyses were performed by the Nei genetic similarity index (Nei, 1978) on the basis of the equation, $\mathrm{SI}=2 \mathrm{Nij} /(\mathrm{Ni}+\mathrm{Nj})$, where $\mathrm{Nij}$ is the number of common bands shared between samples $\mathrm{i}$ and $\mathrm{j}, \mathrm{Ni}$ and $\mathrm{Nj}$ are the total number of DNA bands for genotypes $\mathrm{i}$ and $\mathrm{j}$, respectively. A dendrogram was constructed (Figure 2) on the basis of the similarity matrix data by unweighted pair group method with averages (UPGMA) cluster analysis.

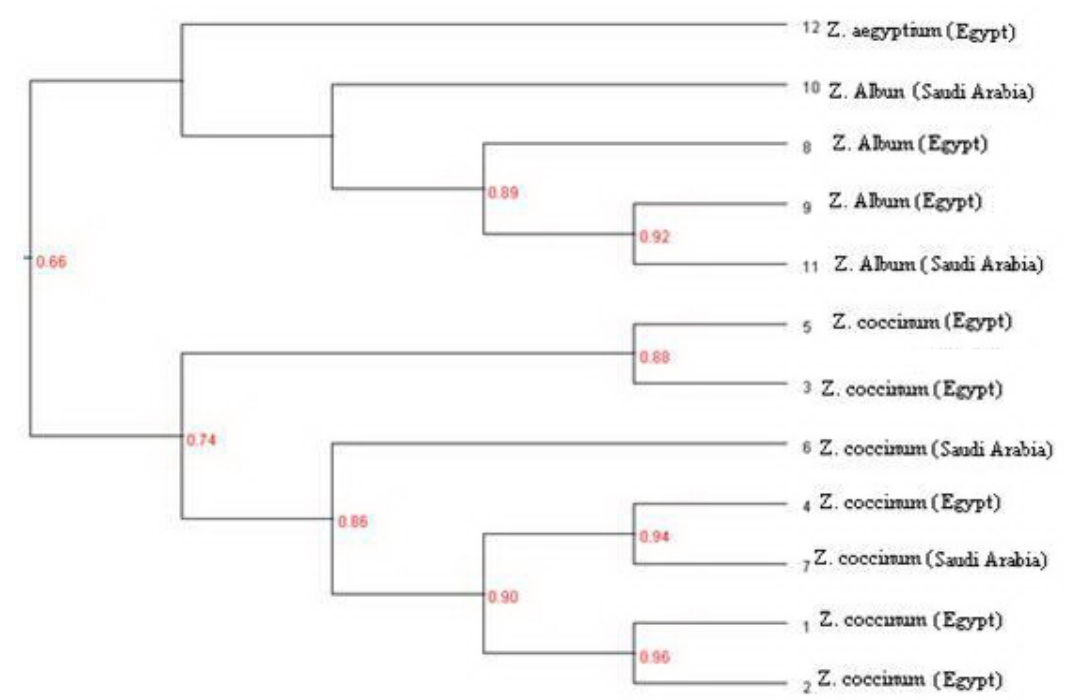

Figure 2. Dendrogram constructed according to UPGMA cluster analysis, based on the similarity index of Nei (1978), showing the genetic relationships within 12 populations of three species of Zygophyllum. 


\section{RESULTS AND DISCUSSION}

The RAPD technique had been successfully used in variety of taxonomic and genetic diversity studies (Rodriguez et al., 1999; Alam et al., 2009), and it was found suitable for use with Zygophyllum species because of its ability to generate reproducible polymorphic bands (Yi et al., 2008) with seeds. A total of 19 RAPD OPERON primers were screened of 12 samples of three species of Zygophyllum (Z. coccineum, Z. album and Z. aegyptium) collected from Egypt and Saudi Arabia. Out of these, only five of the primers (Table 2) that showed reproducible results were chosen to amplify the whole 12 populations (Figure 3). A total of 54 bands were amplified among the three species of Zygophyllum (12 populations), using five primers, and the polymorphic bands. Monomorphic bands are present in all individuals, polymorphic are present in one or more but not all individuals, and unique ones are present in at least one individual not in any other (Mehetre et al., 2004). The mean percentage of polymorphic bands was $83.3 \%$, with molecular sizes ranging from 0.26 to $2.7 \mathrm{~kb}$. Thirteen bands of the 54 were commonly detected in all the samples, so it could be the specific genus bands of Zygophyllum.

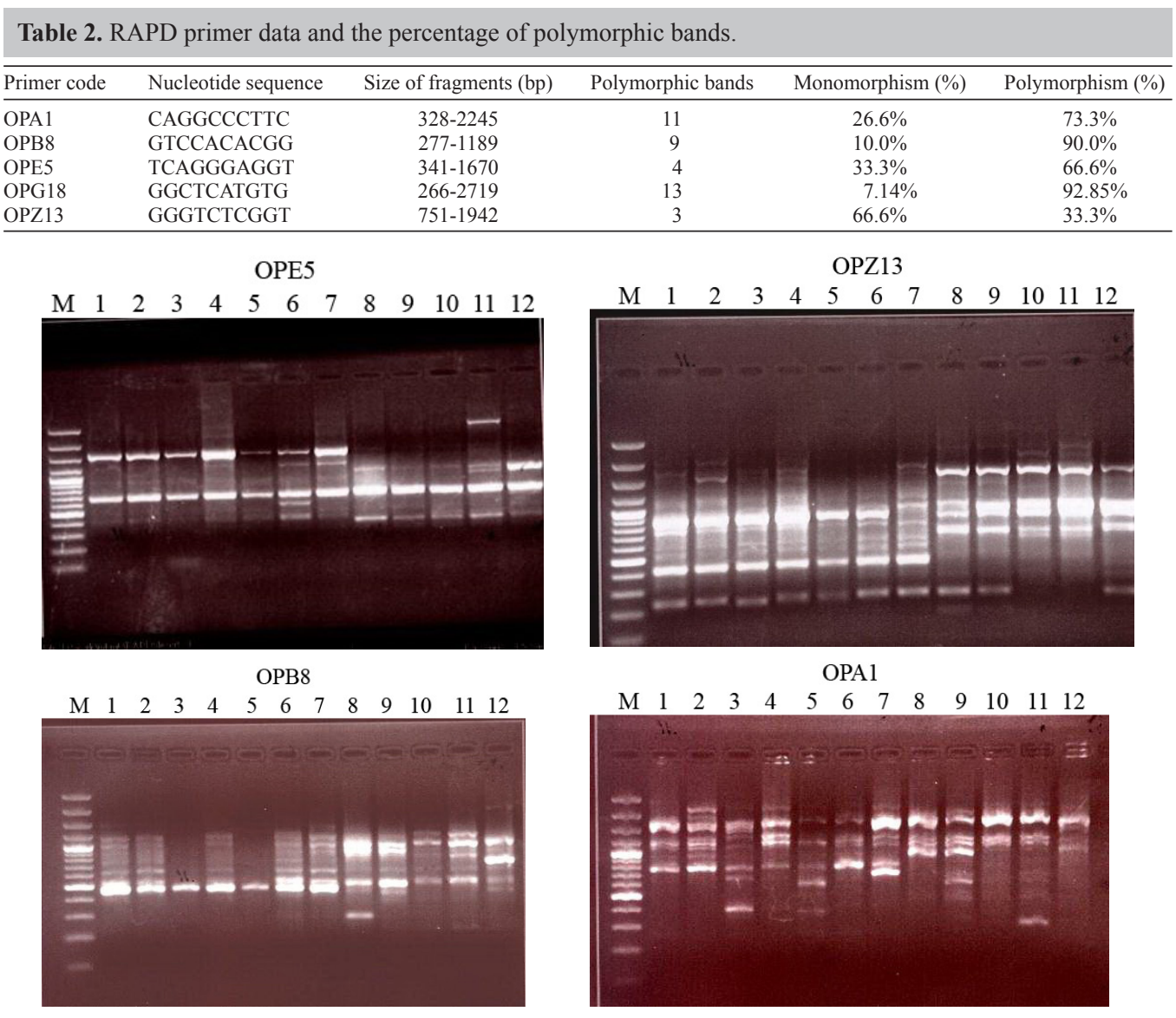

Figure 3. Polymorphic bands generated by different RAPD primers. $\mathrm{M}=$ molecular marker; Lanes 1-12 = Loc1Loc12 populations as indicated in Table 1 . 
The results of total amplified fragments, amplified fragments and specific markers for each species of Zygophyllum (Z. coccineum, Z. album and Z. aegyptium) using RAPDPCR analysis with the five random primers are shown in Table 3 . A total number of 54 amplified fragments were obtained with all primers, which agreed with Welsh and McClelland (1990), who found that simple and reproducible fingerprints of complex genomes can be generated using single primers and PCR. The species specific markers differed among the three species (23 markers) as appear in Table 3: $Z$. coccineum exhibited 15 specific fragments, $Z$. album showed 8 specific markers, while $Z$. aegyptium did not have any specific bands. These bands could be potential species-specific markers after checking that every individual from that species shows the marker in question (Roman et al., 2003). The results of $Z$. coccineum and Z. album confirmed the importance of using RAPD analysis to characterize each species with the appearance of specific markers and produce informative bands that distinguished the two species; similar findings were obtained with few molecular studied of Zygophyllaceae (Sheahan and Mark, 2000; Yang et al., 2000; Yi et al., 2008). Other researchers worked with the same genus but with other species (Arghavani et al., 2010; Thendral et al., 2010).

Table 3. Number of total amplified fragments, amplified fragments and specific markers of the three species of Zygophyllum (Z. coccineum, Z. album and Z. aegyptium) using RAPD analysis with five primers.

\begin{tabular}{|c|c|c|c|c|c|c|c|c|}
\hline \multirow[t]{2}{*}{ Primer } & \multirow[t]{2}{*}{ TAF } & \multicolumn{2}{|c|}{ Z. coccineum } & \multicolumn{2}{|c|}{ Z. album } & \multicolumn{2}{|c|}{ Z. aegyptium } & \multirow[t]{2}{*}{ TSM } \\
\hline & & $\mathrm{AF}$ & SM & $\mathrm{AF}$ & SM & $\mathrm{AF}$ & SM & \\
\hline OPA1 & 15 & 9 & 3 & 9 & 4 & 5 & 0 & 7 \\
\hline OPB8 & 10 & 7 & 5 & 10 & 2 & 8 & 0 & 7 \\
\hline OPE5 & 6 & 5 & 2 & 4 & 0 & 4 & 0 & 2 \\
\hline OPG18 & 14 & 11 & 3 & 9 & 1 & 7 & 0 & 4 \\
\hline OPZ13 & 9 & 5 & 2 & 7 & 1 & 6 & 0 & 3 \\
\hline Total & 54 & 36 & 15 & 39 & 8 & 30 & 0 & 23 \\
\hline
\end{tabular}

$\mathrm{TAF}=$ total amplified fragments; $\mathrm{AF}=$ amplified fragments; $\mathrm{SM}=$ specific markers; $\mathrm{TSM}=$ total specific markers.

Sources of polymorphism in RAPD assay may be due to deletion, addition or substitution of base within the priming site sequence (Williams et al., 1990). High diversity is the reflection of adaptation to environment, which is beneficial to its propagation, conservation of resources, the domestication of wild species, and the screen of specified locus. Dendrogram constructed using the neighbor joining method of cluster analysis separated all the 12 samples of the three species into two clusters. Cluster 1 includes two species: Z. album and Z. aegyptium, which were separated into 2 sub-clusters. Z. aegyptium (Loc12) is in a clad and all populations of Z. album (Loc8, 9, 10, and 11), which were collected from different localities, are in a separate clad; this indicates that both species have a close genetic relationship. Cluster 2 contains seven populations of $Z$. coccineum and these populations were collected from Loc1, Loc2, Loc3, Loc4, Loc5, Loc6 and Loc7, which were from different geographical locations. Geographically isolated individuals tend to accumulate genetic variations during the course of environmental adaptations (Sarwat et al., 2008). Populations from Loc3 and Loc5 were collected from an area surrounded by industries and exposed to environmental pollution and the resulting genetic adaptation. The genetic structure of plant populations reflects the interactions of many different processes, such as the long-term evolutionary history of the species (e.g., shifts in distribution, habitat fragmentation, and/or population isolation), mutation, genetic drift, mating system, gene flow, and selection (Slatkin, 1987; Schaal et al., 1998; Thendral et al., 2010). All of these factors can lead to complex genetic structuring within populations. 
Genetic diversity is of great importance to the sustainability of plant populations (Wang et al., 2007). Based on the above results, there are collections with a high similarity index, even though they may be belonging to geographically different locations. High similarity indices suggest that the populations of the species have close genetic relationship among them. This situation can rise in natural populations when there is a possibility of free/random pollen flow and fertilization. The genetic similarity of the samples slightly correlated with their close geographic locations (Sayed et al., 2009).

For example, the spatial structure of genetic variation can provide information for sampling strategies for ex situ or in situ conservation (Torre et al., 2008). This study was an attempt to establish the genetic diversity background in three species of Zygophyllum with RAPD markers. High levels of polymorphism found in the present study showed that the RAPD marker is a suitable tool for genetic diversity. This study could pave the way for detailed research to understand all the aspects of this divergence to solve a lot of taxonomical problems.

Table 4 shows similarity indices between the twelve populations where the high value indicated a close relationship between the two compared samples and the low value indicated remote relationships between the two populations. The highest similarity value (0.96) was recorded between populations Loc1 (Z. coccineum) from Abu-rudeis, Sinai, Egypt, and Loc2 (Z. coccineum) from Abu-zenima, Sinai, Egypt, indicating that these two populations were closely related to each other according to geographical distribution. On the other hand, the lowest similarity value $(0.50)$ was recorded between populations Loc1 (Z. coccineum) from Abu-rudeis, Sinai, Egypt, and Loc12 (Z. aegyptium) from Demitta, Delta, Egypt, indicating that these were distantly related samples.

\begin{tabular}{|c|c|c|c|c|c|c|c|c|c|c|c|c|}
\hline & Loc1 & Loc2 & Loc3 & Loc4 & Loc5 & Loc6 & Loc7 & Loc8 & Loc9 & Loc 10 & Loc11 & Loc12 \\
\hline Loc1 & 1.00 & & & & & & & & & & & \\
\hline Loc2 & 0.96 & 1.00 & & & & & & & & & & \\
\hline Loc3 & 0.90 & 0.91 & 1.00 & & & & & & & & & \\
\hline Loc4 & 0.89 & 0.90 & 0.93 & 1.00 & & & & & & & & \\
\hline Loc5 & 0.85 & 0.83 & 0.90 & 0.86 & 1.00 & & & & & & & \\
\hline Loc6 & 0.75 & 0.73 & 0.71 & 0.80 & 0.74 & 1.00 & & & & & & \\
\hline Loc7 & 0.74 & 0.72 & 0.71 & 0.76 & 0.77 & 0.88 & 1.00 & & & & & \\
\hline Loc8 & 0.72 & 0.73 & 0.75 & 0.71 & 0.71 & 0.59 & 0.58 & 1.00 & & & & \\
\hline Loc9 & 0.72 & 0.70 & 0.75 & 0.68 & 0.75 & 0.56 & 0.58 & 0.84 & 1.00 & & & \\
\hline Loc 10 & 0.70 & 0.51 & 0.73 & 0.66 & 0.72 & 0.71 & 0.56 & 0.88 & 0.84 & 1.00 & & \\
\hline Loc11 & 0.66 & 0.51 & 0.72 & 0.65 & 0.71 & 0.67 & 0.56 & 0.85 & 0.85 & 0.91 & 1.00 & \\
\hline Loc12 & 0.66 & 0.50 & 0.72 & 0.65 & 0.68 & 0.67 & 0.53 & 0.85 & 0.91 & 0.85 & 0.91 & 1.00 \\
\hline
\end{tabular}

\section{ACKNOWLEDGMENTS}

I. Hammad wishes to thank all Drs. from Mansoura and Helwan University for helping and encouragement.

\section{REFERENCES}

Ahmed AM (2001). Cytological Studies on Genus Zygophyllum in Egypt. Masther's thesis, Faculty of Science, Al-Azhar University, Cairo.

Ait El Cadi M, Khabbal Y, Alaoui K, Faouzi M-A, et al. (2008). Antidiarrhoeal activity of Zygophyllum gaetulum (Activité antidiarrhéique de Zygophyllum gaetulum). Phytothérapie 6: 2-4. 
Alam MA, Gulati P, Aswini KG, Gyan PM, et al. (2009). Assessment of genetic diversity among Podophyllum hexandrum genotypes of northwestern Himalayan region for Podophyllotoxin production. Indian J. Biotechnol. 8: 391-399.

Arghavani A, Asghari A, Shokrpour M and Chmanabad M (2010). Genetic diversity in ecotypes of two Agropyron species using RAPD markers. Res. J. Environ. Sci. 4: 50-56.

Batanouny KH and Ezzat NH (1971). Eco-physiological studies on desert plants. I. Autecology of Zygophyllum species growing in Egypt. Oecologia 7: 170-183.

Beier BA, Chase MW and Thulin M (2003). Phylogenetic relationships and taxonomy of subfamily Zygophylloideae (Zygophyllaceae) based on molecular and morphological data. Plant Syst. Evol. 240: 11-39.

Chalmers KJ, Waugh R, Sprent JI, Simons AJ, et al. (1992). Detection of genetic variation between and within populations of Gliricidia sepium and G. maculata using RAPD markers. Heredity 69 (Pt. 5): 465-472.

Chaturvedi A and Nag TN (2010). Genetic relatedness of the Gossypium species by RAPD analysis. Int. J. Biotechnol. Biochem. 6: 693-700.

Doyle JJ and Doyle JL (1990). Isolation of plant DNA from fresh tissue. Focus 12: 13-15.

El-Hadidi MN (1978). The family Zygophyllaceae in Egypt. I. A proposed classification for the genus Tribulus in Egypt. Bot. Notiser 131: 439-443.

Esselman EJ, Jianqiang L, Crawford DJ, Windus JL, et al. (1999). Clonal diversity in the rare Calamagrostis porteri ssp. insperata (Poaceae): comparative results for allozymes and random amplified polymorphic DNA (RAPD) and intersimple sequence repeat (ISSR) markers. Mol. Ecol. 8: 443-453.

Hoseny AMM (2005). Size structure of Zygophyllum album and Cornulaca monacantha populations in salhyia area, east of Egypt. Int. J. Agric. Biol. 7: 345-351.

Hosny A (1977). New Zygophyllum taxa from Egypt. Bot. Notiser 130: 467-468.

Huff DR, Peakall R and Smouse PE (1993). RAPD variation within and among natural populations of outcrossing buffalograss (Buchloe dactyloides (Nutt.) Engelm.). Theor. Appl. Genet. 86: 927-934.

Landi S, Suiwen H, Dali W and Yingcong Z (2008). Rapid clonal propagation of Zygophyllum xanthoxylon (Bunge) Maxim., an endangered desert forage species. In Vitro Cell. Dev. Biol. Plant 44: 396-400.

Landry BS, Dextraze L and Boivin G (1993). Random amplified polymorphic DNA markers for DNA fingerprinting and genetic variability assessment of minute parasitic wasp species (Hymenoptera: Mymaridae and Trichogrammatidae) used in biological control programs of phytophagous insects. Genome 36: 580-587.

Mashaly IA (2002). Ecological studies on Zygophyllum aegyptium in the Deltaic Mediterranean coast of Egypt. Pak. $J$. Biol. Sci. 5: 152-160.

Mehetre S, Gomes M and Eapen S (2004). RAPD analysis of hybrid nature of the offspring of Gossypium hirsutum x G. raimondii. Curr. Sci. 87: 24-28.

Nasser S and Al-Khalifah N (2004). The role of biotechnology in developing plant resources in desert environment. International Conference on Water Resources \& Arid Environment.

Navarro-Quezada A, Gonzalez-Chauvet R, Molina-Freaner F and Eguiarte LE (2003). Genetic differentiation in the Agave deserti (Agavaceae) complex of the Sonoran desert. Heredity 90: 220-227.

Nei M (1978). Estimation of average heterozygosity and genetic distance from a small number of individuals. Genetics 89: $583-590$

Nesbitt KA, Potts BM, Vaillancourt RE, West AK, et al. (1995). Partitioning and distribution of RAPD variation in a forest tree species, Eucalyptus globulus (Myrtaceae). Heredity 74: 628-637.

Prathepha P and Baimai V (1999). Genetic differentiation in Thai populations of the rare species Afgekia sericea Craib (Leguminosae) revealed by RAPD-PCR assays. Genetica 105: 193-202.

Rodriguez JM, Berke T, Engle L and Nienhuis J (1999). Variation among and within Capsicum species revealed by RAPD markers. Theor. Appl. Genet. 99: 147-156.

Roman B, Alfaro C, Torres AM, Moreno MT, et al. (2003). Genetic relationships among Orobanche species as revealed by RAPD analysis. Ann. Bot. 91: 637-642.

Salim K, Khanda JM and Malik ZA (2010). Development of RAPD markers for authentication of medicinal plant Cuscuta reflexa. EurAsian J. BioSci. 4: 1-7.

Sarwat M, Das S and Srivastava PS (2008). Analysis of genetic diversity through AFLP, SAMPL, ISSR and RAPD markers in Tribulus terrestris, a medicinal herb. Plant Cell. Rep. 27: 519-528.

Sayed M, Hasan Z, Shafie M, Shafie B, et al. (2009). Analysis of random amplified polymorphic DNA (RAPD) of Artemisia capillaries (Worm wood capillary) in east coast of Penisular Malaysia. World Appl. Sci. J. 6: 976-986.

Schaal BA, Hayworth DA, Olsen KM, Rauscher JT, et al. (1998). Phylogeographic studies in plants: problems and prospects. Mol. Ecol. 7: 465-474.

Sheahan MC and Mark WC (2000). Phylogenetic relationships within Zygophyllaceae based on DNA sequences of three plastid regions, with special emphasis on Zygophylloideae. Syst. Bot. 25: 371-384.

Genetics and Molecular Research 9 (4): 2412-2420 (2010) 
Slatkin M (1987). Gene flow and the geographic structure of populations. Science 236: 787-792.

Soliman MI (1995). Cytological studies of Zygophyllum aegyptium in Egypt. J. Environ. Sci. 10: 45-56.

Stewart CN Jr and Excoffier L (1996). Assessing population genetic structure and variability with RAPD data: application to Vaccinium macrocarpon (American Cranberry). J. Evol. Biol. 9: 153-171.

Tackholm V (1974). Students Flora of Egypt. Cairo University Press, Cairo.

Thendral HB, Premalakshmi V and Sekar T (2010). Genetic diversity in Azima tetracantha (Lam) assessed through RAPD analysis. Indian J. Sci. Technol. 3: 170-173.

Torre A de la, Lopez C, Yglesias E and Cornelius JP (2008). Genetic (AFLP) diversity of nine Cedrela odorata populations in Madre de Dios, southern Peruvian Amazon. For. Ecol. Manag. 255: 334-339.

Wang XP, Zou YP and Zhang DM (1996). Problems in the use of RAPD to the study of genetic diversity and systematics. Acta Bot. Sin. 38: 954-962.

Wang W, Chen L, Yang P, Hou L, et al. (2007). Assessing genetic diversity of populations of top mouth culter (Culter alburnus) in China using AFLP markers. Biochem. Syst. Ecol. 35: 662-669.

Welsh J and McClelland M (1990). Fingerprinting genomes using PCR with arbitrary primers. Nucleic Acids Res. 18: 7213-7218.

Williams JG, Kubelik AR, Livak KJ, Rafalski JA, et al. (1990). DNA polymorphisms amplified by arbitrary primers are useful as genetic markers. Nucleic Acids Res. 18: 6531-6535.

Yang TW, Yang YA and Xiong Z (2000). Paternal inheritance of chloroplast DNA in interspecific hybrids in the genus Larrea (Zygophyllaceae). Am. J. Bot. 87: 1452-1458.

Yi L, Jianjun QU, Xiaoming YANG and Lizhe AN (2008). A report on ultra-dry storage experiment of Zygophyllum xanthoxylon seeds. Bot. Stud. 49: 243-251. 